\title{
Microstructural effect on pseudoelastic behaviour of binary Ni-Ti alloys
}

\author{
V. Mertinger, D. Wurzel ${ }^{1}$ and E. Hornbogen
}

\author{
University of Miskolc, Institute of Material Science, Department of Physical Metallurgy, \\ Miskolc-Egyetemváros, Fémtani Tanszék 3515, Hungary \\ ${ }^{1}$ Ruhr-Universität Bochum, Fakultät für Maschinenbau, Institut für Werkstoffe, \\ Gebaeude IA 1/30, Universitätsstr. 150, 44801 Bochum, Germany
}

\begin{abstract}
The effect of various heat treatments on the microstructure and pseudoelastic property of two binary $\mathrm{Ni}-\mathrm{Ti}$ alloys with different $\mathrm{Ni}$ contents were investigated in this work. Some samples of each alloy were produced with three different heat treatments (a) solution heat treated, (b) solution heat treated and aged (c) marformed and aged,. Marforming process was carried out by cold rolling some of the samples in martensitic state. The temperature dependence and reversibility of transformation induced deformation (pseudoelastic behaviour) as well as the conventional yield stress were obtained by tensile test. The formation of $\mathrm{Ni}$ rich precipitates $\left(\mathrm{Ni}_{4} \mathrm{Ti}_{3}\right)$ was only observed in the alloy with higher $\mathrm{Ni}$ content following the ageing process. It was concluded that the microstructure produced by marforming and ageing result in the optimum pseudoelastic properties.
\end{abstract}

\section{INTRODUCTION}

The Ni-Ti alloy system has been of a great interest mainly due to its unique shape memory and pseudoelastic properties which occur in the near equiatomic NiTi alloys. Assuming that the critical temperature of a martensitic transformation depends on thermodynamic equilibrium at the interfaces involved, it would be reasonable to relate the transformation temperature to the chemical compositions of the transforming phases. In addition to chemical composition of the alloy, presence of structural defect may also modify the transformation temperature due to its effect on nucleation and/or propagation of the growing new phase(s). The stress fields caused by dislocations or precipitations aid the formation of the premartensitic $\mathrm{R}$ phase which requires a lower shear forces than the main martensitic transformation. $[1,2,3]$.

Yinong [4] suggested that in order to observe complete pseudoelastic behaviour in an alloy two criteria must be satisfied simultaneously. The first criterion states that the yield strength of the shape memory alloy should increase by introducing dislocations or precipitation hardening. Since the pseudoelasticity is the simultaneous reversal of the stress induced martensite upon unloading it means that the stress induced martensite is thermodynamically unstable relative to austenite. According to the second criterion, the test temperature should exceed the $A_{f}$ temperature (finish temperature of the reverse transformation) [5].

The purpose of this work is to analyse the pseudoelastic behavior and tensile properties of the $\mathrm{Ti}-\mathrm{Ni}$ alloys with different microstructures.

\section{MATERIALS AND EXPERIMENTAL METHODS}

Table 1 shows the nominal chemical compositions of the Ni-Ti alloys which were investigated. In initial state all samples were solution heat treated and then quenched in water. Parts of the samples were aged at $350^{\circ} \mathrm{C}$ or $550^{\circ} \mathrm{C}$ for 6 or 60 or 6000 minutes. In order to increase the extend of lattice defects, such as dislocations, vacancies and subgrain-boundaries, the rest of samples were marformed by rolling at liquid nitrogen temperature before conducting the ageing process as mentioned above. The thermal histories of all tested samples in this work are summarised in Table2. Pseudoelastic behaviour of the samples was studied using a conventional tensile test at various temperatures between $\mathrm{M}_{\mathrm{s}}$ (martensite start upon cooling) and $\mathrm{A}_{\mathrm{f}}$ (austenite finish upon heating) The applied stress was kept low enough to prevent conventional mechanical plastic deformation. 
Table 1. The chemical composition ( $w t \%)$ of alloys

\begin{tabular}{|c|c|c|c|c|c|c|}
\hline Alloy & $\mathrm{Ni}$ & $\mathrm{Cu}$ & $\mathrm{Fe}$ & $\mathrm{C}$ & $\mathrm{O}$ & $\mathrm{Ti}$ \\
\hline $\mathrm{A}$ & 55,2 & $<0,03$ & $<0,05$ & 0,076 & 0,05 & Rest \\
\hline $\mathrm{B}$ & 55,6 & $<0,03$ & $<0,05$ & 0,055 & 0,08 & rest \\
\hline
\end{tabular}

Table 2. Description of different conditions of tested samples

\begin{tabular}{|l|c|c|c|c|c|c|c|c|c|}
\hline \multicolumn{1}{|c|}{ Code } & $\mathbf{1}$ & $\mathbf{2}$ & $\mathbf{3}$ & $\mathbf{4}$ & $\mathbf{5}$ & $\mathbf{6}$ & $\mathbf{7}$ & $\mathbf{8}$ & $\mathbf{9}$ \\
\hline Ni content, wt\% & 55,2 & 55,6 & 55,6 & 55,6 & 55,6 & 55,6 & 55,6 & 55,6 & 55,2 \\
\hline Marforming, \% & - & - & - & - & - & - & 41 & 41 & 63 \\
\hline $\begin{array}{l}\text { Ageing } \\
\text { temperature, }{ }^{\circ} \mathrm{C}\end{array}$ & - & - & 350 & 550 & 550 & 550 & 550 & 550 & 550 \\
\hline Ageing time, $\min$ & - & - & 60 & 6 & 60 & 6000 & 6 & 60 & 6 \\
\hline
\end{tabular}

The conventional yield stress of austenite phase was determined at $200^{\circ} \mathrm{C}$ above $A_{f}$ to insure the stress-induced phase transformation and ageing effects are minimal.

LM and TEM were used to investigate and determine the microstructures of the samples. The size of grains and precipitates was quantitatively measured from TEM micrographs. The transformation temperatures were obtained from DSC measurements.

\section{EXPERIMENTAL RESULTS}

Microstructure: Having annealed all samples, the precipitation of $\mathrm{Ni}_{4} \mathrm{Ti}_{3}$ phase was only observed in the alloy with high $\mathrm{Ni}$ content. Increasing the time and temperature of the annealing process resulted in a growth of $\mathrm{Ni}_{4} \mathrm{Ti}_{3}$ precipitates, whereas the grain size remained almost unchanged. A structural recovery and formation of very fine grains were observed in the case of marformed samples. Fig 1 shows the microstructures of the samples after receiving a thermomechanical treatment. Table 3 outlines the results of a quantitative analysis on the tested samples.

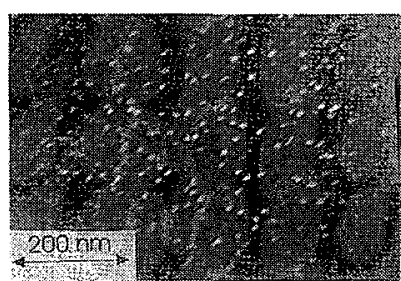

a)

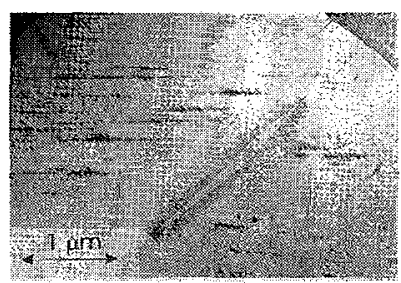

d)

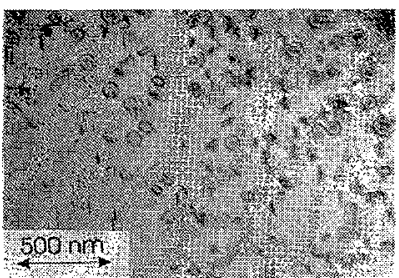

b)

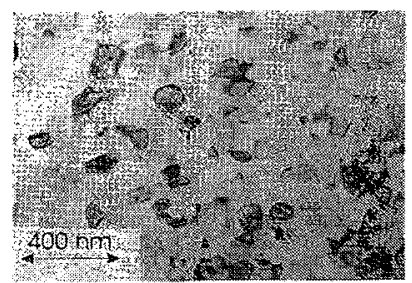

e)

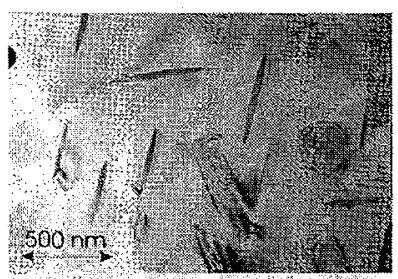

c)

Fig1. TEM micrograph of treated samples with higher $\mathrm{Ni}$ contain a) $\mathrm{SHT}+350^{\circ} \mathrm{C}, 60 \mathrm{~min}$ b) $\mathrm{SHT}+550^{\circ} \mathrm{C}, 6 \mathrm{~min}$, c) $\mathrm{SHT}+550^{\circ} \mathrm{C}, 60 \mathrm{~min}$ d) $\mathrm{SHT}+550^{\circ} \mathrm{C}, 6000 \mathrm{~min}$, e) $\mathrm{SHT}+\mathrm{MF}+550^{\circ} \mathrm{C}, 60 \mathrm{~min}$ 
Table 3. Description of microstructure

\begin{tabular}{|l|c|c|c|c|c|c|c|c|c|}
\hline \multicolumn{1}{|c|}{ Code } & $\mathbf{1}$ & $\mathbf{2}$ & $\mathbf{3}$ & $\mathbf{4}$ & $\mathbf{5}$ & $\mathbf{6}$ & $\mathbf{7}$ & $\mathbf{8}$ & $\mathbf{9}$ \\
\hline $\begin{array}{l}\text { Grain size of } \boldsymbol{\beta}, \\
\boldsymbol{\mu m}\end{array}$ & 45 & 45 & 45 & 45 & 45 & 45 & 0,07 & 0,01 & 0,06 \\
\hline $\begin{array}{l}\text { Size of } \mathrm{Ni}_{4} \mathrm{Ti}_{3} \\
\text { precipitate, } \mu \mathrm{m}\end{array}$ & $\begin{array}{c}\text { No } \\
\text { prec. }\end{array}$ & $\begin{array}{c}\text { No } \\
\text { prec. }\end{array}$ & $<0,02$ & 0,08 & 0,3 & $>2$ & & & \\
\hline
\end{tabular}

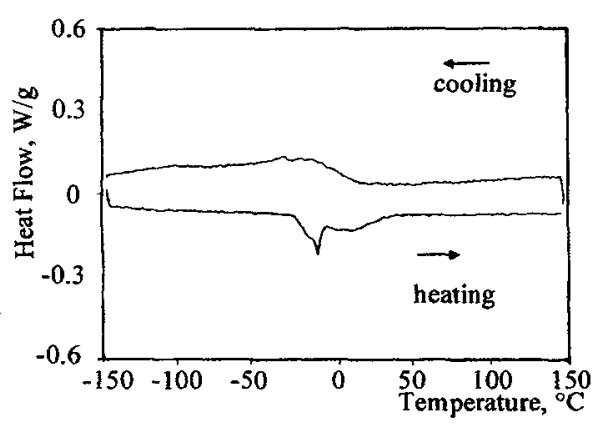

a)

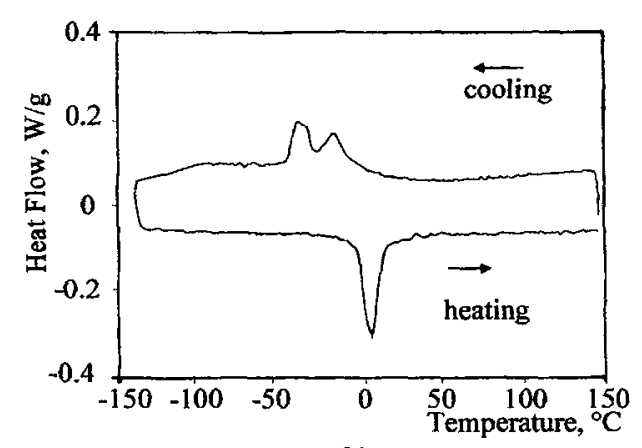

b)

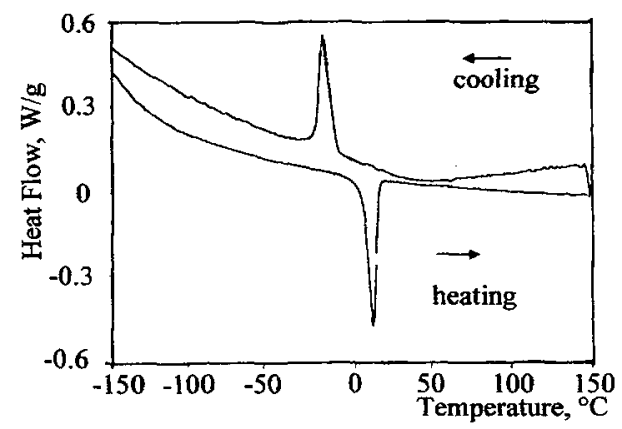

c)

Fig2. DSC curves of sample with higher $\mathrm{Ni}$ contain $\mathrm{SHT}+550^{\circ} \mathrm{C}$ a) $\left.6 \mathrm{~min}, \mathrm{~b}\right) 60 \mathrm{~min}$, c) $6000 \mathrm{~min}$

Transformation temperatures: It can be concluded from DSC analysis that the phase transformation is associated with the formation of $\mathrm{R}$ phase and the transformation temperature changes with the $\mathrm{Ni}$ concentration. By increasing the tempering time or temperature, the volume fraction of $\mathrm{Ni}$ rich precipitates increased leading to a decline in the transformation temperature.

If the precipitation size is fine (code 5) a premartensitic ( $R$ phase) formation takes place and if the size is getting smaller (code 4) the two reactions (martensitic and $R$ phase formation) are more overlapped (Fig 2.). Marforming results also R phase formation.

The transformation temperatures extracted from DSC analysis of 9 different treatments is summarised in Fig 3.

Tensile properties: All the parameters of condition 8 were determined from the tensile tests so the slop of critical stress to induce martenzite and the temperature dependence of the PE yield stress and conventional yielding of austenite are shown in Fig. 4.

The Fig 5 and 6. give an overview of those parameters for the all conditions. 


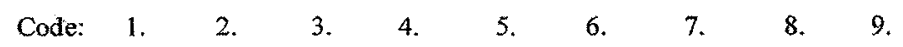

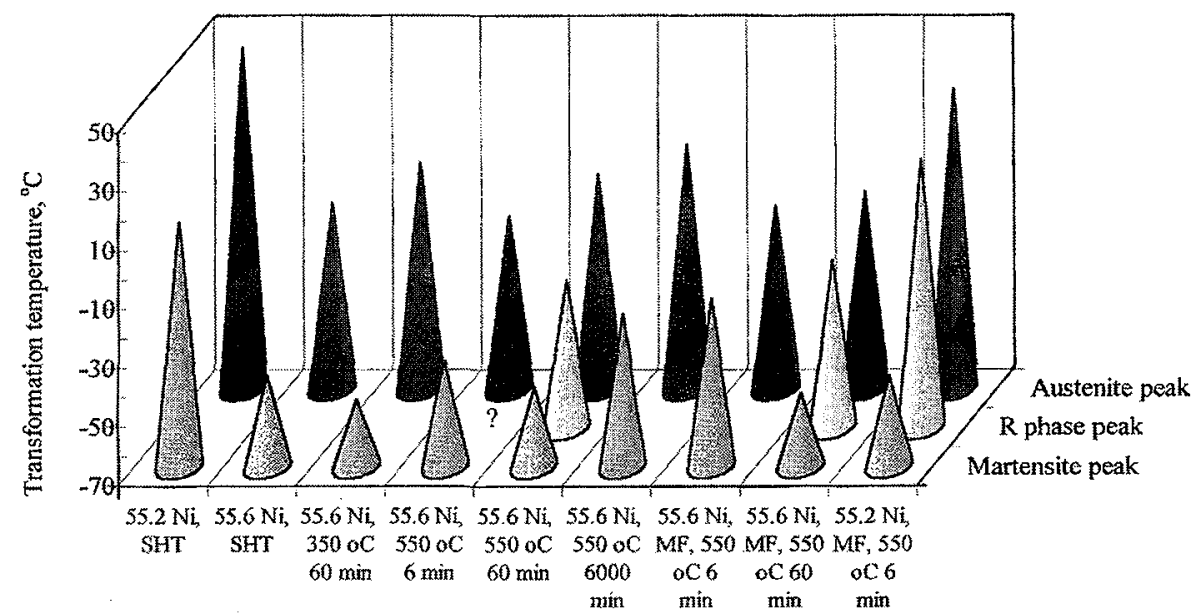

Fig.3 Transformation temperatures of the different conditions

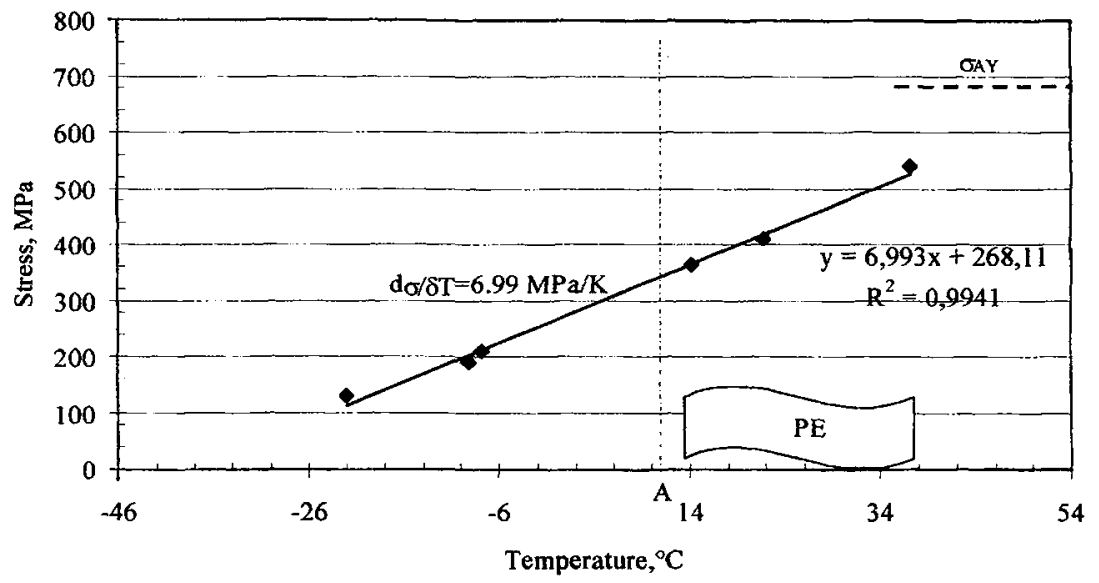

Fig4. Parameters determined from tensile tests of sample condition 8

\section{DISCUSSION}

It was concluded that the formation of $\mathrm{Ni}_{4} \mathrm{Ti}_{3}$ precipitates has three simultaneous effects on the microstructure and transformation temperature of $\mathrm{Ni}-\mathrm{Ti}$ alloy:

- decreasing the Ni content of the matrix, thus, increasing the $\mathrm{M}_{\mathrm{s}}$ temperature,

- decreasing the volume fraction of transformable phase,

- obstructing the movement of the transformation interface due to presence of precipitated particles, therefore, lowering $M_{s}$ temperature and effects on yield stresses. 


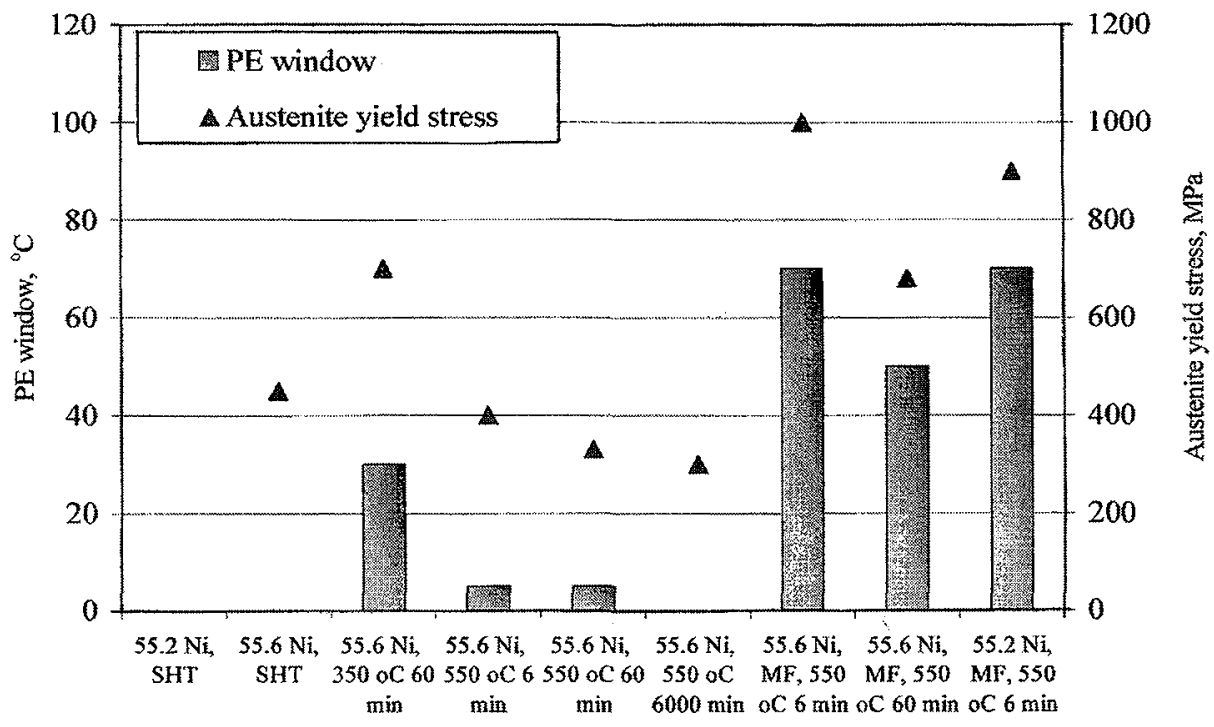

Fig 5. Temperature window for PE and austenite yield stress of all 9 conditions

The samples with the largest $\mathrm{Ni}_{4} \mathrm{Ti}_{3}$ particle size showed an expected rise of $\mathrm{M}_{\mathrm{s}}$ temperature, probably due to the lower Ni concentration of the matrix. On the other hand, formation of finecoherent precipitates widened the hysteresys curve, proving that there was a strong obstruction in the course of reversed phase transformation.

The formation of medium size precipitates had no substantial effect on the transformation temperature, implying that the obstruction effect of the particles was balanced by the higher content of $\mathrm{Ni}$ which remained in the matrix.

The presence of the coherent-small precipitates increased the austenite yield strength but decreased the slope of critical stress, though, the semicoherent precipitates had an opposite effect (Fig6.).

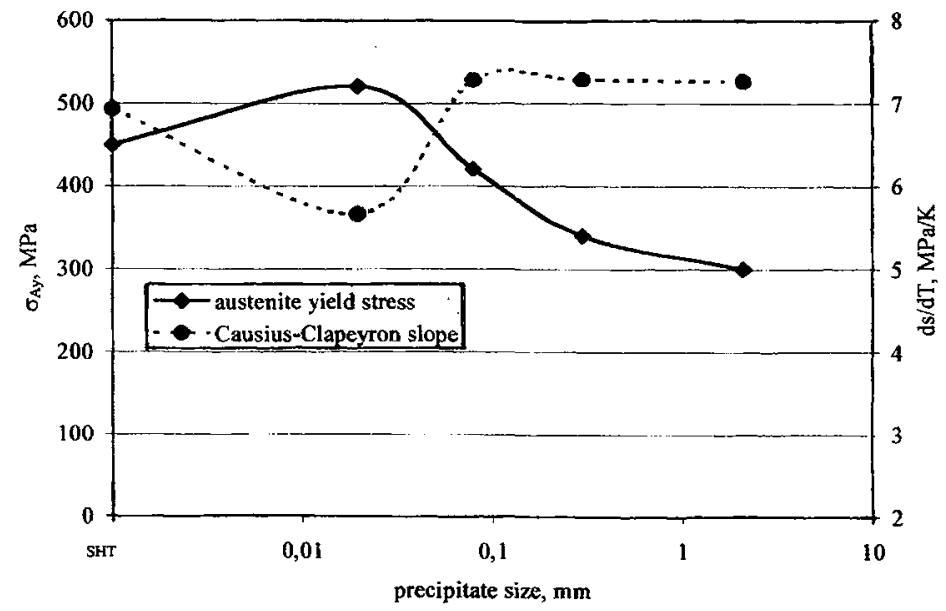

Fig 6. Precipitation size effect on austenite yield stress and Calusius-Clapeyron slope 
Mechanical treatment has four major effects:

- lowering $\mathrm{M}_{\mathrm{s}}$ temperature as a result of work hardening effect,

- enhancing premartensitic reaction $(\beta \rightarrow R \rightarrow M)$,

- increasing the yield stress up to $1000 \mathrm{MPa}$

- increasing pseudo-elastic window.

Lowering the $\mathrm{M}_{\mathrm{s}}$ temperature was more substantial in the case of the alloy with Ni:55.6\% because the transformation front is more impeded by precipitated particles.

The analysis of the conventional yield stress showed not only a hardening effect due to the precipitation is involved, but also the yield strength increases drastically from 300 to $1000 \mathrm{MPa}$. The increased conventional yield strengths leads to the stability of pseudo -elastic state. An increasing tendency of the PE temperature range was observed among the different alloys ranging from solute solution treated to aged, and finally to marformed taged ones.

The stress required for the onset of martensitic transformation can be describe by the ClausiusClapeyron equation:

$$
\frac{d \sigma_{\beta a}}{d T}=\frac{S_{\beta \alpha}}{\varepsilon_{\beta \alpha}} \rho=\frac{h_{\beta \alpha}}{\varepsilon_{\beta a} T_{\beta \alpha}} \rho
$$

The parameters obtained from tensile tests and the measured date from the DSC analysis are in a good agreement (Table 4.)

Table 4. Calculated and measured entropy of transformation $\left(S_{\beta \alpha}\right)$ and respectively Clausius -Clapeyron slope (do/dT) obtained from DSC and tensile test (TT) results.

\begin{tabular}{|c|c|c|c|c|c|c|c|c|c|c|c|c|c|c|c|c|c|c|}
\hline Code & & & & & & & & & & & & & 7 & & & & & \\
\hline & DSC & TT & $\overline{D S C}$ & TT & DSC & TT & $\overline{D S C}$ & $\mathrm{TT}$ & DSC & TT & DSC & $\mathrm{TT}$ & $\mathrm{DSC}$ & TT & DSC & TT & $\overline{D S C}$ & TT \\
\hline $\begin{array}{c}S_{\beta \alpha} \\
*^{*} 10^{-2} \\
\mathrm{~J} / \mathrm{gK}\end{array}$ & 8,3 & 8,4 & 7,4 & 7,28 & ? & 6,0 & 8,7 & 8,4 & 8,1 & 7,7 & 7,4 & 7,2 & $?$ & 7,3 & 4,7 & 6,5 & 6,7 & 6,6 \\
\hline $\begin{array}{l}\mathrm{d} \sigma / \mathrm{dT} \\
\mathrm{MPa} / \mathrm{K}\end{array}$ & 7,9 & 8,0 & 7,1 & 6,9 & ? & 6,5 & 7,6 & 7,3 & 7,6 & 7,3 & 7,5 & 7,3 & $?$ & 7,2 & 5,0 & 7,0 & 6,8 & 6,7 \\
\hline
\end{tabular}

\section{SUMMARY}

Mechanical, pseudoelastic behavior of two binary $\mathrm{Ni}$ - $\mathrm{Ti}$ alloys with different $\mathrm{Ni}$ contents and various heat treatments were investigated in this work. The favorable mechanical behavior (high strength, wide PE range etc.) was achieved after marforming and short time aging of both alloys.

This treatment results in a fine microstructure consisting of small grains and precipitates. Meanwhile, introduction of dislocations results in the formation of $R$ phase and increase in both yield strength and work hardening of austenite, as well as widening pseudoelastic window.

\section{ACKNOWLEDGEMENT}

Thanks are due to the Union of German Academies of Science for supporting one of the authors (VM). The work is part of SFB 459.

\section{REFERENCES}

[1] L.Bataillard, J.-E.Bidaux, R.Gotthardt: Philosophical Magazine A, 1998, Vol.78, No.2,327-344

[2] D.Treppmann, E.Hornbogen, D.Wurzel: J.de Phys. IV,C8,5 1995, 596-574

[3] E.Hornbogen: Acta metall. 33,1985,595-601

[4] Yinong Liu,S.P.Galvin: Acta mater. Vol.45,No11.4431-4439, 1997

[5] K.Otsuka, C.M. Wayman: Shape Memory Materials, Cambridge University Press, 1998, 58-69 